\title{
PENGARUH TEMPERATURE, LAMA TIMBUNAN DAN DIMENSI TIMBUNAN TERHADAP TERJADINYA SWABAKAR
}

\author{
Siti Hardianti ${ }^{1)}$, Billi $^{2)}$ \\ 1Program Studi Teknik Pertambangan Batubara Politeknik Akamigas Palembang, 30257, Indonesia \\ 2Program Studi Teknik Pertambangan Batubara Politeknik Akamigas Palembang, 30257, Indonesia \\ Corresponding Author E-mail: siti.hardianti2@gmail.com
}

\begin{abstract}
PT Bukit Asam, Tbk Tarahan Port Unit has 4 stockpiles where each stockpile has a different capacity, stockpile-1 has a capacity of 60.000 MT, stockpile-2 has a capacity of 250.000 MT which is divided into 2 parts namely sea and land direction, stockpile-3 has a capacity of 250.000 MT which is divided into 7 valuebs, namely 0-6 and stockpile-4 has a capacity of 300.000 MT. The study was conducted at the stockpile-2 location which has a storage capacity of 250.000 MT. Locations in stockpile-2 found the discovery of a burnt. The location point is point 1 of the stockpile heap. Based on the results of field analysis, the effect that causes the self-burning is air temperature at that point at $59^{\circ} \mathrm{C}$. Other causes that influence the occurrence of burnt burners are the length of time for coal stockpiles to reach 15-30 days and the dimensions of the cone-shaped embankment that have the potential to cause the burnt burnt, because the wind that hits the coal pile will be even greater. Burning incidents in stockpile-2 must be managed. Handling efforts that can be done include applying the FIFO (First in first out) stockpiling method, monitoring the temperature of the pile, making compaction periodically and reducing the height of the pile.
\end{abstract}

Abstrak: PT Bukit Asam, Tbk Unit Pelabuhan Tarahan memiliki 4 stockpile dimana masing-masing stockpile memiliki kapasitas yang berbeda, stockpile-1 memiliki kapasitas 60.000 MT, stockpile-2 memiliki kapasitas 250.000 MT yang terbagi menjadi 2 bagian yaitu arah laut dan arah darat, stockpile-3 memiliki kapasitas 250.000 MT yang terbagi menjadi 7 valueb yaitu 0-6 dan stockpile-4 memiliki kapasitas sebesar 300.000 MT. Penelitian dilakukan pada lokasi stockpile-2 yang memiliki kapasitas penyimpanan sebesar 250.000 MT. Lokasi pada stockpile-2 terdapat penemuan terjadinya swabakar. Titik lokasi tersebut adalah titik 1 dari bagian timbunan stockpile. Berdasarkan hasil analisis lapangan, menujukkan pengaruh yang menyebabkan timbulnya swabakar ialah temperature udara pada titik tersebut sebesar $59^{\circ} \mathrm{C}$. Sebab lain yang mempengaruhi terjadinya swabakar adalah lamanya waktu penimbunan batubara yang mencapai 15-30 hari dan dimensi timbunan yang berbentuk kerucut terpancung yang berpotensi menyebabkan swabakar, karena angin yang menerpa tumpukan batubara akan semakin besar. Kejadian swabakar pada stockpile-2 harus dilakukan upaya penanganan. Upaya penanganan yang dapat dilakukan antara lain menerapkan metode penimbunan FIFO (First in first out), memantau temperature timbunan, melakukan pemadatan secara berkala dan mengurangi tinggi timbunan.

Kata Kunci : Stockpile, swabakar, temperature, lama timbunan, dimensi timbunan.

\section{PENDAHULUAN}

\subsection{Latar Belakang}

Swabakar atau spontaneous combustion atau disebut juga self combustion adalah salah satu fenomena yang terjadi pada batubara pada waktu batubara tersebut disimpan atau di storage/stockpile dalam jangka waktu tertentu.

Kerugian bila terjadi swabakar di stockpile dapat menyebabkan ekspor maupun impor batubara akan terhambat dan akan menyebabkan kerugian bagi perusahaan salah satunya adalah permintaan kualitas yang diinginkan konsumen tidak dapat terpenuhi akibat berkurangnya kualitas batubara yang telah tersedia di stockpile.

Agar permintaan dari pihak konsumen seperti PLTU dan pabrik-pabrik yang membutuhkan batubara selalu terpenuhi, maka perusahaan penambangan batubara harus memproduksi batubara secara berkelanjutan dari target produksi yang telah ditetapkan pada rencana produksi batubara. Perusahaan juga harus menjaga stockpile batubara agar terhindar dari terjadinya swabakar, agar kualitas batubara tetap selalu terjaga.

Beberapa langkah yang dapat ditempuh guna pencegahan terjadinya swabakar antara lain, pengecekan rutin temperature temporary 
stockpile dengan menggunakan alat Termocouple. Apabila temperature mencapai $50^{\circ} \mathrm{C}-60^{\circ} \mathrm{C}$, maka akan dilakukan penanganan seperti spreading, kompaksi stockpile dan lain-lain. Sudut timbunan yang besar juga mengakibatkan perubahan peningkatan temperature timbunan lebih cepat karena batubara berinteraksi secara terus menerus maka akan dilakukan penangan seperti kompaksi stockpile. Waktu penyimpanan batubara tidak terlalu lama di stockpile merupakan upaya pencegahan terjadinya swabakar, FIFO (First in First Out) dimana batubara yang terdahulu masuk harus di keluarkan atau dimuat terlebih dahulu. Hal ini dimaksudkan untuk mengurangi resiko degradation dan pemanasan batubara, karena semakin lama tumpukan batubara disimpan akan semakin banyak waktu proses pemanasan untuk bekerja (Ambak, 2015).

Maka berdasarkan hal tersebut dilakukan analisis mengenai pengaruh temperature, lama timbunan dan dimensi timbuanan terhadap terjadinya swabakar di stockpile-2 PT Bukit Asam, Tbk. Unit Pelabuhan Tarahan.

\subsection{Rumusan Masalah}

Penelitian ini dilakukan karena sering terjadi swabakar atau spontaneous combustion pada stockpile di PT Bukit Asam, Tbk. Unit Pelabuhan Tarahan.

\subsection{Batasan Masalah}

Batasan masalah dalam penelitian ini adalah:

1. Penelitian dilakukan pada stockpile-2 PT Bukit Asam, Tbk. Unit Pelabuhan Tarahan pada jenis kalori batubara AL-72 LS.

2. Penelitian dibatasi pada pengaruh perubahan temperature, lama timbunan dan dimensi timbunan yang berada di stockpile-2 pada jenis kalori AL-72 LS

3. Penanganan dan pencegahan terjadinya proses swabakar di stockpile-2.

\subsection{Tujuan Penelitian}

Tujuan dalam penelitian ini adalah :
1. Menganalisis pengaruh temperature, lama timbunan, dan dimensi timbunan terhadap terjadinya swabakar.

2. Mengetahui upaya penanganan dan pencegahan terhadap terjadinya swabakar.

\subsection{Manfaat Penelitian}

Manfaat dalam penelitian ini adalah:

1. Mengetahui pengaruh temperature, lama timbunan, dan dimensi timbunan terhadap terjadinya swabakar.

2. Perusahan dapat gambaran tentang upaya yang bisa dilakukan untuk pengendalian terjadinya swabakar.

\section{TEORI DASAR}

\subsection{Swabakar (Spontaneous Combustion)}

Swabakar atau Spontaneous combustion atau disebut juga self combustion adalah salah satu fenomena yang terjadi pada batubara pada waktu batubara tersebut disimpan atau di storage/stockpile dalam jangka waktu tertentu.

\subsection{Proses Terjadinya Swabakar}

Faktor-faktor umum yang menyebabkan timbulnya swabakar dapat dikelompokkan sebagai berikut (Mulyana, 2005):

1. Terjadinya reaksi oksidasi eksotermis didalam batubara.

2. Terjadinya reaksi oksidasi eksotermis didalam batubara.

3. Jika panas tidak dapat dilepaskan ke luar permukaan stockpile maka akan terjadi peningkatan suhu didalam tumpukan stockpile sehingga akan memicu timbulnya api pada batubara.

4. Batubara telah lama disimpan atau di stock pada stockpile terbuka terlalu lama tanpa pemadatan.

5. Kecepatan angin yang menerpa stockpile.

6. Monitoring batubara yang kurang baik.

2.3 Faktor-Faktor Penyebab Terjadinya Proses Swabakar, Antara Lain :

\section{Lama penimbunan}


Semakin lama batubara tertimbun akan semakin banyak panas yang tersimpan di dalam timbunan, karena volume udara yang terkandung dalam timbunan semakin besar, sehingga kecepatan oksidasi menjadi semakin tinggi.

2. Alat yang digunakan dalam metode penimbunan

Dalam timbunan batubara perlu mendapatkan pemadatan. Dengan adanya pemadatan ini akan dapat menghambat proses terjadinya swabakar batubara, karena ruang antar butir diantara material batubara berkurang, adapun alat yang digunakan untuk pemadatan adalah bulldozer atau excavator.

3. Kondisi penimbunan

Pengaruh kondisi penimbunan terhadap proses swabakar batubara, yaitu sebagai berikut :

a. Tinggi timbunan

Tinggi timbunan yang terlalu tinggi akan menyebabkan semakin banyak panas yang terserap, hal ini dikarenakan sisi miring yang terbentuk akan semakin panjang, sehingga daerah yang tak terpadatkan akan semakin luas dan akan mengakibatkan permukaan yang teroksidasi semakin besar. Untuk batubara bituminous yang ditimbun lebih dari 30 hari sebaiknya tinggi timbunan maksimum 6 meter. Sedangkan untuk timbunan batubara lignit lebih dari 14 hari tinggi timbunan maksimum 4 meter.

\section{b. Ukuran butir}

Pada dasarnya semakin besar luas permukaan yang berhubungan langsung dengan udara luar, semakin cepat proses pembakaran dengan sendirinya berlangsung. Sebaliknya semakin besar ukuran bongkah batubara, semakin lambat proses swabakar. Ukuran butir batubara juga mempengaruhi kecepatan dari proses oksidasi. Semakin seragam besar ukuran butir dalam suatu timbunan batubara, semakin besar pula porositas yang dihasilkan dan akibatnya semakin besar permeabilitas udara luar untuk dapat beredar di dalam timbunan batubara.

\section{c. Sudut timbunan}

Adalah sudut yang dibentuk oleh suatu tumpukan batubara pada timbunan (stockpile). Sudut tersebut sebaiknya lebih kecil dari angle of repose timbunan batubara. Pada umumnya material yang berukuran kasar memiliki angle of repose yang lebih besar bila dibandingkan dengan material berukuran halus. Sudut timbunan batubara pada stockpile yang cukup ideal, yaitu $38^{\circ}$.

Tabel. 2.1 Angle Of Repose Beberapa Material

\begin{tabular}{|c|c|}
\hline Material & Angle of Repose \\
\hline Clay, ditambang & $30^{\circ}-40^{\circ}$ \\
\hline Coal, dari tambang & $38^{\circ}$ \\
\hline Graver, dari tambang & $38^{\circ}$ \\
\hline Limestone, dari tambang & $30^{\circ}-40^{\circ}$ \\
\hline Bijih mangan & $39^{\circ}$ \\
\hline Batuan, bngkah & $20^{\circ}-29^{\circ}$ \\
\hline Pasir kering & $35^{\circ}$ \\
\hline
\end{tabular}

Sumber : Andri Hermawan, 2001

\section{Suhu swabakar}

Semua jenis batubara mempunyai kemampuan untuk terjadinya proses swabakar, tetapi waktu yang diperlukan dan besarnya suhu yang dibutuhkan untuk proses swabakar batubara ini tidak sama. Untuk batubara yang mempunyai rank rendah memerlukan waktu yang lebih pendek dan suhu yang lebih rendah bila dibandingkan dengan batubara yang mempunyai tingkat yang tinggi.

\subsection{Upaya Pencegahan Swabakar (Spontaneous Combustion) \\ Menurut Muchjidin (2006), ada} beberapa anjuran dalam melakukan penumpukkan batubara untuk mengurangi 
kecenderungan terjadinya swabakar, antara lain :

\section{Segregasi}

Segregasi dari batubara berukuran besar di sekeliling dasar tumpukan batubara harus dihindari karena akan membantu pergerakan bebas dari udara. Sehingga udara dapat melakukan penetrasi ke dalam timbunan batubara yang akan memicu terjadinya oksidasi. Apabila penetrasi udara terjadi secara terus menerus temperature timbunan akan meningkat dan akhirnya akan memicu terjadinya swabakar. Oleh karena itu, perlu penggunaan batubara halus untuk melapisi permukaan suatu stockpile agar dapat mengurangi penetrasi udara.

2. Memadatkan permukaan yang menghadap ke arah angin

Untuk menyimpan batubara yang relatife lama, baik batubara golongan rendah maupun batubara golongan tinggi, sebaiknya setiap slope tumpukan dipadatkan, khususnya yang menghadap ke arah angin. Bahwa pemadatan permukaan berarti mengurangi penetrasi oksigen kedalam tumpukan batubara dalam tumpukan tersebut, pemadatan harus dilakukan secara berkala pada lapisan timbunan batubara dengan ketebalan antara 0,5 sampai 1 meter. Pemadatan juga diperlukan untuk menjaga kualitas dan memperkecil risiko swabakar (spontaneous combustion) pada stockpile dalam waktu yang lama.

3. Mengurangi ketinggian stockpile Tujuan mengurangi ketinggian stockpile adalah untuk mengurangi impact dari angin yang menerpa stockpile. Semakin besar luas permukaan yang diterpa angin semakin besar tingkat oksidasi yang terjadi, yang berarti pula semakin besar kemungkinannya untuk terjadinya swabakar atau pembakaran spontan, mengurangi ketinggian stockpile dapat dengan luasan penumpukan diperbesar. Apabila luasan area stockpile tidak mencukupi, maka pemadatan harus dilakukan. Pemadatan stockpile dapat dilakukan layer by layer atau single compaction. Mengurangi sudut slope tumpukan. Hal ini dimaksudkan untuk mengurangi impact angin yang menerpa tumpukan batubara. Dengan melandaikan bagian permukaan yang menghadap ke arah angin, berarti juga mengurangi penetrasi angin atau oksigen masuk ke dalam tumpukan.

\section{METODOLOGI PENELITIAN}

\subsection{Jenis Penelitian}

Jenis penelitian yang dilakukan pada penelitian ini adalah penelitian kuantitatif dengan proses penelitiannya langsung melakukan observasi lapangan.

\subsection{Waktu dan Tempat Penelitian}

Penelitian ini dilakukan selama 2 bulan. Penelitian ini dilakukan di PT Bukit Asam, Tbk. Unit Pelabuhan Tarahan di Satuan Kerja Kendali Produk.

\subsection{Metode Penelitian}

Masalah-masalah yang dibahas pada penelitian ini, dapat menggunakan beberapa metode penyelesaiannya sebagai berikut: Penulis menggabungkan antara studi pustaka dengan data-data observasi lapangan. Urutan pekerjaan penelitian, yaitu :

1. Studi literatur

Studi Literatur adalah sumber-sumber data yang dapat digunakan sebagai data awalan terhadap penelitian yang akan dilakukan di stockpile, dimulai dari batubara masuk kedalam stockpile hingga keluar, serta situasi stockpile, dan lain-lain.

2. Observasi lapangan

Observasi lapangan adalah upaya pengamatan yang dapat dilakukan dengan meninjau langsung ke stockpile seperti : 
a. Pengamatan terhadap kegiatan yang berkaitan dengan operasi penanganan batubara di stockpile-2.

b. Pengamatan terhadap masalah yang sering di stockpile-2

3. Pengumpulan Data

Dalam penelitian ini terdapat dua jenis data, yaitu :

a. Data primer yaitu data yang diperoleh secara langsung di lapangan, antara lain :

1. Titik pengamatan stockpile-2

2. Data temperature stockpile-2

3. Dimensi timbunan stockpile-2

b. Data sekunder yaitu data yang diambil dari data yang sudah ada di perusahaan dan referensi-referensi yang berhubungan dengan penelitian ini seperti lama timbunan batubara di stockpile-2

4. Pengolahan Data

Data yang telah diperoleh kemudian diolah berdasarkan jenis data, kemudian dilakukan analisis serta perhitungan sesuai dengan kebutuhan dan tujuan dari penelitian ini.

\section{HASIL DAN PEMBAHASAN \\ 4.1 Lokasi Pengambilan Data Temperature}

PT Bukit Asam, Tbk Unit Pelabuhan Tarahan memiliki 4 stockpile dimana masing-masing stockpile memiliki kapasitas yang berbeda, stockpile-1 memiliki kapasitas sebesar 60.000 MT, stockpile-2 memiliki kapasitas sebesar 250.000 MT yang terbagi menjadi 2 bagian yaitu arah laut dan arah darat. Kapasitas stockpile-3 sebesar 250.000 MT yang terbagi menjadi 7 valueb yaitu 0-6 dan stockpile-4 memiliki kapasitas sebesar 300.000 MT. Penelitian mengenai pengaruh temperature, lama timbunan dan dimensi timbunan ini difokuskan pada stockpile-2 pada jenis kalori batubara AL-72 LS.
Berikut lokasi 12 titik pengambilan data temperature pada stockpile-2 $\mathrm{AL}$ 72 LS

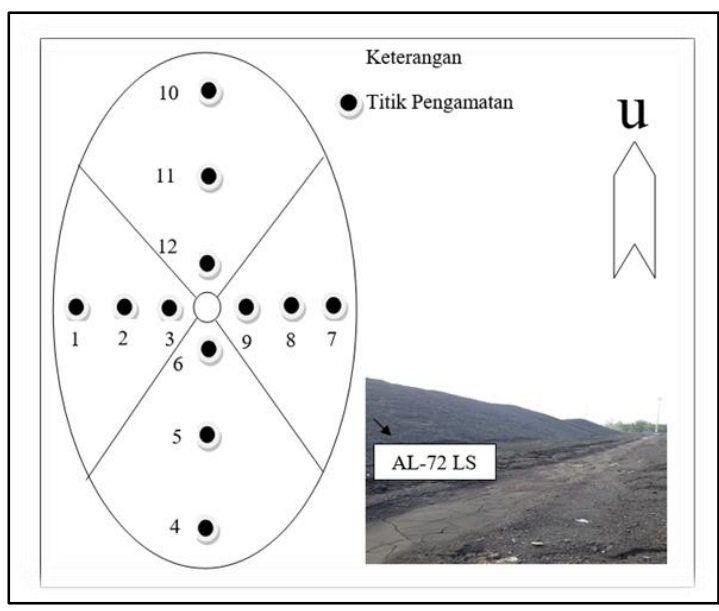

Gambar 4.1. Lokasi Pengambilan Data

\subsection{Pengukuran Temperature pada Stockpile-2 AL 72 LS}

Pengukuran temperature dilakukan pada siang hari di stockpile-2 AL-72 LS dari tanggal 14-29 Mei 2019 pada 12 titik pengamatan. Dari hasil pengamatan didapatkan data sebagai berikut:

Tabel 4.1 Temperature Timbunan Stockpile2 AL 72 LS Pada Siang Hari

\begin{tabular}{|c|c|c|c|c|c|c|c|c|c|c|c|c|}
\hline \multirow{2}{*}{ Tanggal } & \multicolumn{12}{|c|}{ Titik Pengamatan $\left({ }^{\circ} \mathrm{C}\right)$} \\
\hline & 1 & 2 & 3 & 4 & 5 & 6 & 7 & 8 & 9 & 10 & 11 & 12 \\
\hline 14-Mei-19 & 35 & 36 & 33 & 36 & 34 & 35 & 37 & 34 & 35 & 36 & 38 & 35 \\
\hline 15-Mei-19 & 41 & 39 & 40 & 39 & 42 & 37 & 40 & 40 & 38 & 40 & 39 & 41 \\
\hline 16-Mei-19 & 40 & 38 & 37 & 39 & 40 & 37 & 38 & 42 & 36 & 38 & 37 & 37 \\
\hline 17-Mei-19 & 36 & 37 & 34 & 39 & 38 & 38 & 41 & 39 & 40 & 40 & 38 & 37 \\
\hline 18-Mei-19 & 37 & 36 & 35 & 38 & 36 & 37 & 38 & 35 & 37 & 39 & 36 & 35 \\
\hline 19-Mei-19 & \multirow{2}{*}{\multicolumn{12}{|c|}{ Tidak dilakukan Pengamatan (Hari Libur) }} \\
\hline 20-Mei-19 & & & & & & & & & & & & \\
\hline 21-Mei-19 & 39 & 38 & 38 & 38 & 36 & 37 & 38 & 35 & 37 & 39 & 36 & 38 \\
\hline 22-Mei-19 & 59 & 41 & 39 & 44 & 41 & 43 & 47 & 40 & 41 & 43 & 40 & 39 \\
\hline 23-Mei-19 & 38 & 39 & 37 & 37 & 39 & 38 & 38 & 40 & 39 & 36 & 38 & 38 \\
\hline 24-Mei-19 & 41 & 39 & 37 & 40 & 38 & 39 & 42 & 40 & 39 & 40 & 39 & 37 \\
\hline 25-Mei-19 & 38 & 37 & 37 & 39 & 35 & 34 & 38 & 36 & 37 & 36 & 33 & 34 \\
\hline 26-Mei-19 & \multirow{2}{*}{\multicolumn{12}{|c|}{ Tidak dilakukan Pengamatan (Hari Libur) }} \\
\hline 27-Mei-19 & & & & & & & & & & & & \\
\hline 28-Mei-19 & 36 & 39 & 39 & 41 & 39 & 37 & 37 & 42 & 40 & 39 & 36 & 38 \\
\hline 29-Mei-19 & 39 & 37 & 40 & 38 & 38 & 40 & 41 & 41 & 41 & 41 & 39 & 40 \\
\hline
\end{tabular}

Dari 12 hari pengamatan di 12 titik pada stockpile-2 AL-72 LS, didapatkaan hasil bahwa terjadi swabakar di tanggal 12 Mei 2019 pada lokasi titik 1, dengan temperature $59^{\circ} \mathrm{C}$ yang melebih temperature titik kritis yaitu $\geq 50^{\circ} \mathrm{C}$ sehingga membuat 
batubara bereaksi dan menyebabkan terjadinya swabakar.

\subsection{Lama Timbunan}

Batubara yang ditimbun pada stockpile-2 AL-72 LS PT Bukit Asam, Tbk. Unit Pelabuhan Tarahan paling lama ditimbun selama 21 dan paling cepat 1 hari dalam 1 minggu .

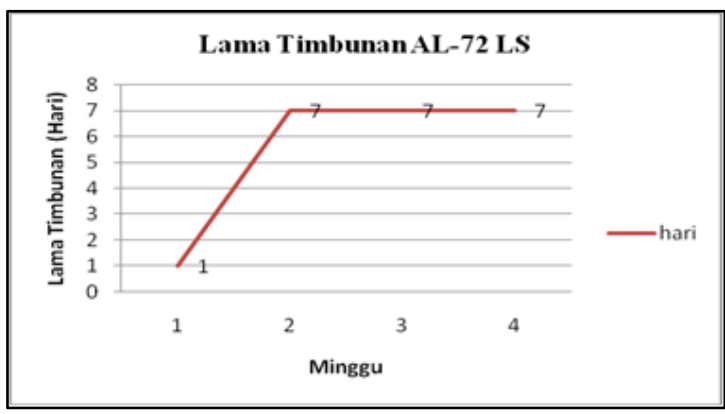

Gambar 4.2 Grafik Lama Timbunan pada Stockpile-2 AL-72 LS

Dilihat dari (Gambar 4.2) diatas lamanya penimbunan batubara yang ada di timbunan arah laut jenis batubara AL-72 LS, pada minggu ke-1 lama timbunan 1 hari dalam 1 minggu, pada minggu ke-2 lama timbunan 7 hari dalam 1 minggu, pada minggu ke-3 dan ke-4 lama timbunan 7 hari dalam 1 minggu.

Pada batubara AL-72 LS jenis timbunan arah laut terjadi swabakar karena penimbunan yang cukup lama, dimana batubara tersebut digunakan untuk memenuhi kebutuhan pasar ekspor.

Semakin lama batubara ditimbun di stockpile-2 maka batubara tersebut akan menghasilkan banyak panas yang tersimpan di dalam timbunan sehingga temperature batubara meningkat dan berpotensi terjadinya swabakar.

Penimbunan batubara di stockpile-2 PT. Bukit Asam,Tbk. Unit Pelabuhan Tarahan bersifat sementara karena batubara yang ditimbun akan diangkut dari stockpile ke kapal berjangka waktu \pm 1 minggu tergantung permintaan dari konsumen, berbeda dengan batubara jenis antrasit yang di timbun lebih lama dan bisa mencapai waktu 15-30 hari dikarenakan kadar kalorinya yang lebih tinggi dan permintaan konsumen yang tidak terlalu banyak. Upaya pencegahan yang tepat yang bisa dilakukan untuk mencegah swabakar akibat lamanya penimbunan batubara adalah memaksimalkan metode FIFO (First in-first out), dimana batubara yang akan dijual kepada konsumen diutamakan diambil dari stockpile batubara yang lebih dulu berada di stockpile dibandingkan mengunakan batubara yang baru datang dari gerbong kereta api.

Pengaruh lama timbunan terhadap terjadinya swabakar adalah semakin lama batubara terekspose dengan udara, maka semakin besar kemungkinan batubara tersebut mengalami oksidasi yang berarti semakin besar kemungkinan terjadinya swabakar. Batubara yang terakumulasi jumlahnya setiap bulan akan menyimpan panas, akibatnya sirkulasi udara menjadi tidak lancar di dalam area timbunan. Semakin lama batubara tertimbun akan semakin banyak panas yang tersimpan di dalam timbunan, karena volume udara yang terkandung di dalam timbunan semakin besar sehingga kecepatan oksidasi semakin tinggi, hal ini lah yang menyebabkan terjadinya swabakar batubara di area timbunan. Sebaiknya dilakukan monitoring lama timbunan secara berkala agar bisa mengurangi terjadinya swabakar.

\subsection{Dimensi timbunan}

Data Dimensi timbunan meliputi panjang, lebar dan bentuk timbunan. Dari hasil pengukuran di lapangan didapatkan data ukuran panjang, lebar dan bentuk timbunan sebelum dan setelah terjadinya swabakar pada Stockpile-2 AL-72 LS (Tabel 4.2.)

Tabel 4.2 Pengukuran Timbunan Sebelum dan Setelah Terjadinya Swabakar di Stockpile-2

\begin{tabular}{|c|c|}
\hline Dimensi & $\begin{array}{c}\text { Pola Penimbunan } \\
\text { (Cone Ply) }\end{array}$ \\
\hline $\begin{array}{c}\text { Bentuk } \\
\text { Timbuanan }\end{array}$ & Kerucut \\
\hline $\begin{array}{c}\text { Pengukuran Timbunan Sebelum } \\
\text { Terjadinya Swabakar }\end{array}$ \\
\hline Panjang & 22,2 Meter \\
\hline Lebar & 27,7 Meter \\
\hline Tinggi & 15 Meter \\
\hline Pengukuran Timbunan Sesudah \\
Terjadinya Swabakar \\
\hline Panjang & 22 Meter \\
\hline Lebar & 27,2 Meter \\
\hline Tinggi & 15 Meter \\
\hline
\end{tabular}


2. Sudut

Sudut tumpukan yang terbentuk dari suatu tumpukan sebaiknya lebih kecil dari angle of repose tumpukan batubara (Widodo, 2009). Kemiringan area tumpukan batubara dapat dimaksimalkan pada sudut sebesar $30^{\circ}$, dimana untuk batubara dengan peringkat yang rendah seperti lignite dan sub-bituminous memiliki angle of repose sebesar $38^{\circ}$. Pada area timbunan batubara tinggi 15 meter, sudut kemiringan tumpukan sudah mencapai $47^{\circ}$. Tinggi timbunan batubara dan besarnya sudut kemiringan sangat berkaitan dengan arah angin dan keselamatan kerja, karena semakin tinggi dan terjal timbunan akan mempengaruhi aliran angin yang masuk ke rongga timbunan batubara dan berpotensi menimbulkan swabakar, sedangkan berkaitan dengan keselamatan kerja, timbunan yang terlalu tinggi dan terjal akan mengganggu stabilitas timbunan dan berpotensi menyebabkan longsor.

Sudut yang dibentuk dari timbunan batubara merupakan sudut yang terbentuk secara alami hasil dari alat curah batubara, besaran sudut yang terbentuk $47^{\circ}$. Stacker reclaimer (SR) adalah alat yang digunakan untuk mengeruk dan mencurahkan batubara yang telah melalui belt conveyor menuju stockpile (stacking) dan mengambil kembali bahan curahan seperti batubara dari stockpile untuk dikirim kembali melalui belt conveyor ke proses pemanfaatan atau pengolahan (reclaiming). Stacker Reclaimer terdiri dari conveyor, bucket wheel dan tripper.

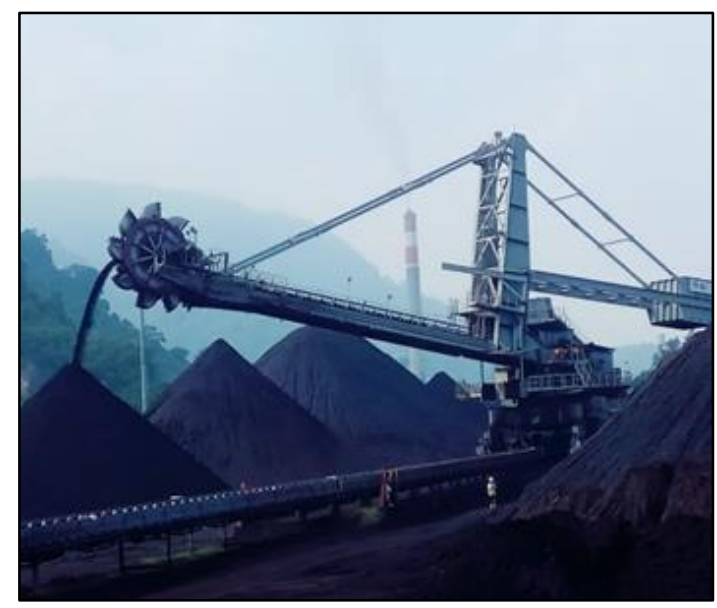

Gambar 4.3 Stacker Reclaimer
Prinsip kerja stacking adalah dengan mengerakan conveyor pada boom tripper yang menuju boom bucket dan mencurahkan batubara ke stockpile. Prinsip kerja reclaiming adalah dengan mengerakan conveyor boom tripper dan boom bucket ke arah stockpile, dan juga dengan memutar bucket wheel guna mengambil coal dari tumpukan batubara untuk diteruskan dan diangkut melalui conveyor sampai masuk ke kapal. Pada stacker dengan kapasitas 2600 tph dan saat reclaimer dengan kapasitas 3500 tph.

Gambar 4.4 Timbunan Stockpile-2 Arah Laut

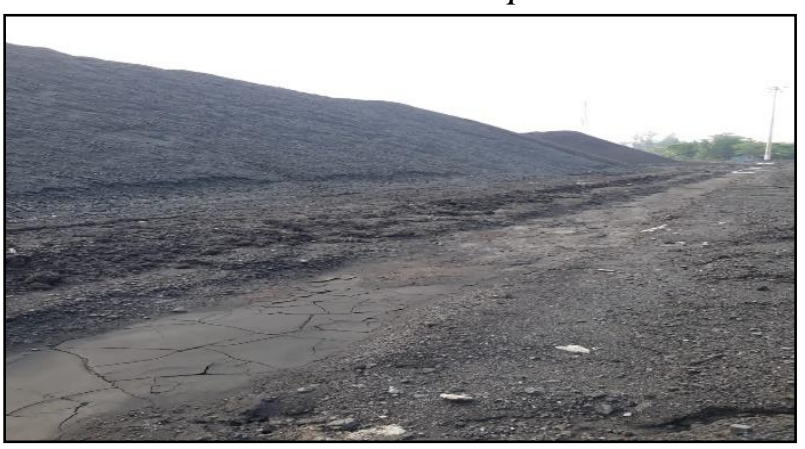

Sudut timbunan yang besar mengakibatkan perubahan peningkatan temperature timbunan lebih cepat karena batubara berinteraksi secara terus menerus dengan udara. Penimbunan batubara pada stockpile ini dilakukan hingga penuh, tinggi timbunan berdasarkan pengukuran yang dilakukan di lapangan adalah 15 meter.

Bentuk timbunan batubara di area stockpile-2 PT. Bukit Asam, Tbk. Unit Pelabuhan Tarahan berbentuk kerucut dikarenakan loading batubara menggunakan Stacker Reclaimer. Kondisi stockpile-2 batubara saat tidak mengalami pemadatan atau pemancungan karena loading pembongkaran dan pemuatan menggunakan alat mekanis Stacker Reclaimer.

\section{Tinggi Timbunan}

Tinggi timbunan yang diperuntukkan untuk batubara dengan kualitas rendah direkomendasikan 4-6 meter. Berdasarkan hasil penelitian tinggi area timbunan adalah 15 m. Tumpukan yang terlalu tinggi akan 
menyebabkan semakin banyak panas yang terserap. Sebaiknya tinggi timbunan di kurangi agar angin yang menerpa sisi tumpukan batubara tidak terus menerus.

\section{Pola penimbunan}

Pola penimbunan batubara pada stockpile-2 ini menggunakan pola penimbunan cone ply. Pola timbunan dengan bentuk kerucut pada salah satu ujungnya sampai tercapai ketinggian yang dikehendaki dan dilanjutkan menurut panjang stockpile. Pola ini menggunakan alat curah. Seperti stacker reclaimer.

\section{Pembuatan saluran air di sekeliling} stockpile

Sistem penirisan diperlukan untuk mengalirkan air dari rembesan timbunan batubara yang akhirnya akan dialirkan ke kolam pengendapan. Sistem penirisan yang terdapat pada stockpile-2 kurang ditangani dengan baik. Hal ini terlihat dari bentuk saluran air yang sebagian besar tertutup dan tersumbat oleh batubara yang semakin turun dari tumpukan stockpile. Pemeliharaan juga tidak dilakukan secara berkala dan kurang dalam pengawasan terutama pada saat musim hujan (Gambar 4.5)

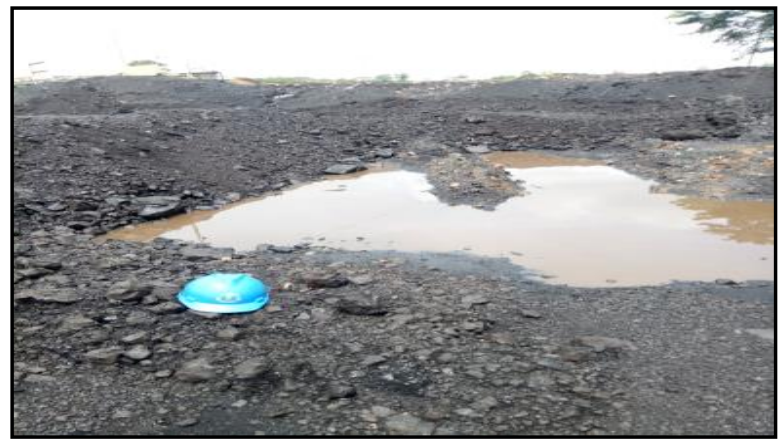

Gambar 4.5 Saluran Terbuka pada Stockpile

\subsection{Upaya Pencegahan Terjadinya Swabakar}

Berdasarkan hasil penelitian yang dilakukan di stockpile-2 AL-72 LS, maka untuk mencegah terjadinya proses swabakar pada timbunan batubara harus dilakukan beberapa penanganan yang baik, seperti :

a. Metode penimbunan dan pembongkaran FIFO (Fist In-Fist Out)
Dalam kegiatan penimbunan dan pembongkaran yang dilakukan, dengan pola chevcon metode ini tidak memungkinkan dilakukannya pembongkaran dengan metode FIFO, karena batubara yang terlebih dahulu ditimbun berada pada lapisan yang paling bawah. Untuk memperbaiki metode penimbunan dan pembongkaran yang dilakukan, maka akan menambah biaya untuk melakukan metode ini.

b. Pemantauan temperature timbunan

Pemantauan Temperature timbunan dilakukan secara berkala yaitu 2 kali dalam 1 hari, terutama pada batubara yang telah tertimbun lama, suhu dan titik pengamatan dicatat dan data yang diperoleh dianalisis untuk mengetahui ada tidaknya gejala akan terjadinya swabakar. Memperhatikan tanda-tanda awal terjadinya swabakar adalah hal yang sangat penting dalam upaya pencegahan swabakar. Namun pada saat melakukan penelitian, pemantauan suhu timbunan tidak dilakukan secara berkala karena alat yang akan digunakan tidak tersedia.

c. Pemadatan secara berkala

Pada saat penelitian pemadatan secara berkala tidak dilakukan karena akan menambah biaya yang cukup besar. Pemadatan hanya dilakukan 1 hari satu kali dengan menggunakan bulldozer pada setiap stockpile dengan tujuan pengontrolan dan pencegahan terjadinya swabakar, sehingga pada stockpile tersebut tidak kembali terjadi swabakar.

d. Mengurangi tinggi timbunan

Tujuan untuk mengurangi ketinggian timbunan adalah untuk mengurangi angin yang menerpa stockpile, semakin luas permukaan yang diterpa angin semakin besar tingkat oksidasi yang terjadi yang berarti semakin besar pula kemungkinan untuk terjadinya swabakar.

\subsection{Penanganan Swabakar}

Upaya penanganan yang dilakukan oleh PT Bukit Asam, Tbk. Unit Pelabuhan 
Tarahan pada saat terjadi swabakar selama penelitiaan, khususnya di stockpile-2 AL-72 LS adalah dengan melakukan pemberaian dan pemadatan menggunakan alat mekanis bulldozer.

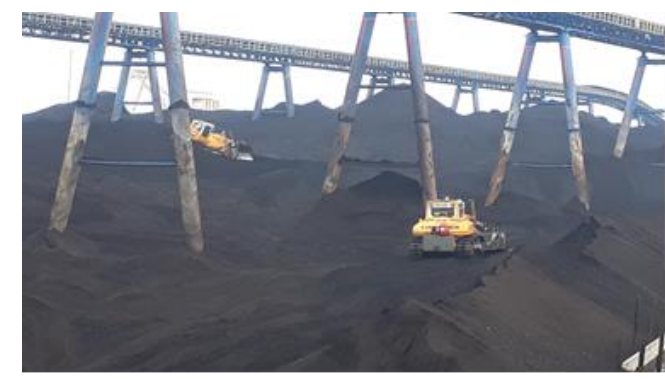

Gambar 4.18 Kegiatan Pemberaian dan Pemadatan Batubara

\section{KESIMPULAN DAN SARAN}

\subsection{Kesimpulan}

Dari hasil penelitian dan pengamatan di lapangan maka didapatkan kesimpulan sebagai berikut :

1. Pada saat penelitian di stockpile-2 AL72 LS bulan Mei-Juli 2019, terjadinya swabakar satu kali dengan temperature $59^{\circ} \mathrm{C}$, melebih temperature titik kritis $\geq 50^{\circ} \mathrm{C}$ sehingga membuat batubara bereaksi dan menyebabkan swabakar.

2. Berdasarkan hasil penelitian di lapangan lama timbunan sangat berpengaruh karena semakin lama batubara ditimbun, maka akan menghasilkan banyak panas yang tersimpan di dalam timbunan tersebut sehingga temperature batubara meningkat dan berpotensi terjadinya swabakar.

3. Dimensi timbunan stockpile2 AL-72 LS yang berbentuk kerucut menyebabkan bagian dari sisi samping timbunan akan dikenai udara bebas yang luas, sehingga bentuk tersebut mempengaruhi terjadinya proses reaksi antar udara luar dengan batubara secara terus menerus dan memicu terjadinya swabakar.

\subsection{Saran}

Berdasarkan kesimpulan yang didapat dari hasil penelitian yang telah dilakukan, maka terdapat beberapa saran yang dapat diberikan sebagai berikut :

1. Sebaiknya pada stockpile-2 dilakukan monitoring temperature secara berkala pagi, siang dan sore agar dapat meminimalisir terjadinya swabakar.

2. Sebaiknya dalam penimbunan batubara menerapkan metode FIFO (First In First Out) dimana batubara yang akan di jual kepada konsumen diutamakan diambil dari stockpile batubara yang telah duluan berada di stockpile dibandingkan mengunakan batubara yang baru datang dari gerbong kereta api.

3. Sebaiknya pada stockpile-2 bentuk timbunanannya dibuat bentuk limas terpancung supaya besar timbuan tidak terlalu tinggi agar mengurangi angin yang menerpa stockpile, karena semakin luas permukaan yang diterpa angin maka semakin besar tingkat oksidasi yang terjadi sehingga semakin besar pula kemungkinan untuk terjadinya swabakar.

\section{DAFTAR PUSTAKA}

Andri, Hermawan, 2001, "Pengenalan Umum Batubara”, Coal Quality Control \& Quantity, Sucifida

Carpenter, Anne M. 1999. Management Of Coal Stockpile. IEA Coal Reseach

Gerrard Widodo. 2009. Upaya Menghindari Kebakaran Tumpukan Batubara. Berita PPTM. No. 11 dan 12. Bandung

Muchjidin. 2006. Pengendali Mutu Dalam Industri Batubara. ITB Bandung

Mulyana, Hana. 2005. Kualitas batubara dan Management Stockpile. Yogyakarta: Geoservices LTD

Sukandarrumidi. 2006. Batubara dan Pemanfaatannya. Yogyakarta: Gajah Mada University Press. 
Sukandarrumidi. 2004. Batubara dan Pemanfaatannya. Yogyakarta: Gajah Mada University Press.

Trisno dan Yohanes Suryadi Ambak. 2015. Kajian Teknis Pencegahan Swabakar Batubara di PT Bukit Baiduri Energy Kabupaten Kutai Kartanegara Provinsi Kalimantan Timur. Jurnal Geologi Pertambangan. Volume (2):1. 